\title{
Efeito do condicionamento osmótico e sombreamento na germinação e no crescimento inicial das mudas de angico (Anadenanthera falcata Benth. Speg.)
}

MOTA, L.H.S. '; *SCALON, S.P.Q.'; MUSSURY, R.M. ${ }^{2}$

${ }^{1}$ Mestrando em Agronomia, Produção Vegetal Faculdade de Ciências Agrárias, Universidade Federal da Grande Dourados-UFGD, Rodovia Dourados Itahum, km 12, Caixa Postal 533, CEP: 79804970, Dourados, MS, leandromota22@bol.com.br; ²Professoras da UFGD, *silvanascalon@ufgd.edu.br; maramussury@ufgd.edu.br

RESUMO: Devido à devastação de áreas do Cerrado, muitas espécies nativas encontramse ameaçadas de extinção e devido à ampla utilização de Anadenanthera falcata, estudos sobre a ecofisiologia da germinação e do crescimento das mudas tornam-se necessários. $O$ presente trabalho objetivou avaliar o efeito do condicionamento osmótico e do sombreamento na germinação e no crescimento inicial de mudas de angico. As sementes foram pré-embebidas em soluções de diferentes concentrações de $\mathrm{PEG}$ e $\mathrm{KNO}_{3}$ e incubadas em temperatura de $10^{\circ} \mathrm{C}$ e $20^{\circ} \mathrm{C}$ durante 12 e 24 horas. Após estes períodos as sementes foram secas até atingirem os teores iniciais de umidade, sendo posteriormente colocadas para germinar em BOD na temperatura de $20-30^{\circ} \mathrm{C}$ em regime fotoperiódico de $8 \mathrm{~h}$ luz e $16 \mathrm{~h}$ de escuro. O tratamento testemunha e os pré-condicionamentos com $\mathrm{KNO}_{3}(-1,0 \mathrm{MPa})$ e PEG (-1,0 MPa) proporcionaram os melhores resultados de germinação em BOD. As sementes foram semeadas em bandejas e posteriormente transplantadas para embalagens plásticas, permanecendo sob telado coberto com sombrite de $50 \%$ e $70 \%$ de sombreamento e a pleno sol. Em BOD, os tratamentos de osmo-condicionamento, reduziram de forma negativa a germinação das sementes. Sob sombreamento, as doses avaliadas não influenciaram na emergência do angico, entretanto, sementes tratadas com $\mathrm{KNO}_{3}(-1,0 \mathrm{MPa})$ tiveram maior índice de velocidade de emergência sob pleno sol apresentando melhor desenvolvimento quando mantidas até os 145 dias de idade.

Palavras-chave: angico, condicionamento osmótico, germinação, PEG $600, \mathrm{KNO}_{3}$

ABSTRACT: Osmotic conditioning and light on seed germination and growth of seedlings Anadenanthera falcata Benth. Speg. Due to the devastation of the Cerrado areas, many native species are threatened with extinction, and due to the widespread use of Anadenanthera falcata, studies on the ecophysiology of seed germination and seedling growth are necessary. This study aimed to evaluate the priming and shading effects on the germination and early growth of angico seedlings. The seeds were pre-soaked in solutions with different concentrations of PEG and $\mathrm{KNO}_{3}$ and incubated at $10^{\circ} \mathrm{C}$ and $20^{\circ} \mathrm{C}$ for 12 and 24 hours. After these periods the seeds were dried until reaching the initial moisture levels, and subsequently incubated in BOD at the temperature of $20-30^{\circ} \mathrm{C}$ under photoperiods of $8 \mathrm{~h}$ of light and $16 \mathrm{~h}$ of dark. The control treatment and pre-conditioning with $\mathrm{KNO}_{3}(-1.0 \mathrm{MPa})$ and PEG (-1.0 MPa) presented the best germination results in BOD. The seeds were sown in trays and then transplanted to plastic packages, remaining in a greenhouse covered with $50 \%$ and $70 \%$ shading, in full sun. In BOD, the priming treatments decreased the germination of seeds. Under shade, the doses evaluated did not affect the emergence of angico, however, seeds treated with $\mathrm{KNO}_{3}(-1.0 \mathrm{MPa})$ had a greater EVI, in full sun and showed a better development when maintained up to 145 days of age.

Keywords: angico, osmotic condition, germination, PEG 6000, $\mathrm{KNO}_{3}$

\section{INTRODUÇÃO}

Com o ritmo acelerado da devastação das florestas, as áreas nativas vêm sendo degradadas e gradativamente reduzidas como conseqüência do desenvolvimento da agricultura, tal como ocorreu em Mato Grosso do Sul para o cultivo de soja em áreas de Cerrado. Assim, muitas espécies vegetais estão

Recebido para publicação em 18/10/2010 
restritas a determinadas áreas ou até mesmo sendo extintas, dentre elas, algumas de valor medicinal (Martins \& Silva, 2001). Portanto, a melhoria do sistema de produção de mudas dessas espécies é necessária devido ao aumento na procura para a produção comercial, bem como para a recuperação de áreas degradadas (Nietsche et al., 2004).

As espécies nativas normalmente apresentam desuniformidade de germinação o que pode ser superado pelo osmocondicionamento, que consiste numa pré-embebição em solução de potencial osmótico conhecido que regula a hidratação das sementes permitindo a ativação dos processos metabólicos que levam à síntese de enzimas e quebra das moléculas de reserva nutritiva sem que ocorra a emissão da raiz primária. Os efeitos do condicionamento osmótico, frequentemente relatado para plantas cultivadas e hortaliças, proporciona maior uniformidade e sincronização da germinação, elevados índices de emergência, e favorece o desenvolvimento das plântulas mesmo em solos com baixos teores de água, promove maior taxa de crescimento da parte aérea, e maior rapidez no amadurecimento das plantas (Marcos Filho, 2005).

Rego et al. (2007) observaram que a velocidade de absorção de água pelas sementes é proporcional à quantidade de água disponível, entretanto, a germinação pode não ocorrer quando o potencial de água for inferior a determinado ponto crítico, o qual varia com a espécie. Esses autores sugerem a eficiência da técnica do précondicionamento das sementes em soluções osmóticas para assegurar uma performance superior na germinação das sementes. Esses autores observaram efeito negativo do osmocondicionamento para as sementes de angico branco (Anadenanthera colubrina (Vell.) Brenan).

Entretanto, são escassas as informações na literatura sobre o osmocondicionamento para espécies arbóreas e principalmente sobre as sementes de angico preto, as quais apresentam melhor germinação após armazenamento por 100 dias (Scalon Filho et al., 2006), embora perca a viabilidade após seis meses de armazenamento em ambiente não controlado (Carvalho, 2003).

No sistema de produção de mudas, além da otimização da germinação, o crescimento e a qualidade das mudas também têm sido objeto de pesquisas. A intensidade luminosa, a temperatura, a concentração de $\mathrm{CO}_{2}$ e a umidade do solo, são fatores que afetam a atividade fotossintética e, consequentemente, influem no desenvolvimento das plantas. A luz é primordial não só por fornecer energia para a fotossíntese, mas também por fornecer sinais que regulam seu desenvolvimento por meio de receptores sensíveis a diferentes intensidades e qualidade espectral (Gonçalves et al., 2006).

O angico preto (Anadenanthera falcata Benth. Speg) é uma espécie com ampla distribuição geográfica podendo ser encontrada em regiões savânicas, cerrado, e cerradão do Brasil. O chá da casca da árvore combate tosse e bronquite, sendo cicatrizante e utilizada para tratar feridas e ulcerações, combate também anginas e disenteria (Santos, 2002). A espécie apresenta crescimento moderado a rápido, sendo aproveitada com sucesso para reflorestamentos de áreas degradadas, em terrenos erodidos e para locais sujeitos a inundações periódicas de rápida duração ou períodos de encharcamento leve. A germinação varia de 55 a $80 \%$ em condições favoráveis, entretanto, em ambientes desfavoráveis essa germinação é desuniforme e baixa. A espécie é heliófila e medianamente tolerante a baixas temperaturas (Carvalho, 2003). Embora seja espécie conhecida, são escassas as informações na literatura sobre a ecofisiologia e produção de mudas.

Tentando confirmar a hipótese de que as sementes de angico respondem ao polietilenoglicol apresentando uniformidade e aumento no potencial germinativo logo após a dispersão e que a germinação das sementes e o crescimento das mudas pode ser favorecido pelo sombreamento, considerando que $A$. falcata é classificada como heliófila, objetivou-se avaliar o condicionamento osmótico e o sombreamento na germinação e no crescimento inicial das mudas dessa espécie.

\section{MATERIAL E MÉTODO}

Experimento 1: Efeito do condicionamento, tempo de embebição e da temperatura sobre a germinação das sementes

As sementes de angico foram coletadas em diversas matrizes em Dourados no Mato Grosso do Sul, cidade situada a $22^{\circ} 14^{\prime} 16^{\prime \prime S}$ e $54^{\circ} 48^{\prime} 02^{\prime \prime} \mathrm{W}$ e altitude média de $452 \mathrm{~m}$, com clima classificado como Cwa e precipitação média anual de 1500 $\mathrm{mm}$. A temperatura média anual é de $22^{\circ} \mathrm{C}$. $\mathrm{O}$ solo, originalmente sob vegetação de cerrado, é de topografia plana e classificado como latossolo vermelho distroférrico de textura argilosa (Mato Grosso do Sul, 1990).

A pré-embebição foi realizada em caixas gerbox forradas com duas folhas de papel filtro umedecidas com $15 \mathrm{~mL}$ das respectivas soluçõesteste: 1) Polietilenoglicol 6000 (-0,5 MPa); 2) PEG $6000(-1,0 \mathrm{MPa})$; 3) PEG $6000(-0,5 \mathrm{MPa})+\mathrm{KNO}_{3}$ (-0,5 MPa); 4) PEG $6000(-1,0 \mathrm{MPa})+\mathrm{KNO}_{3}(-1,0$ $\mathrm{MPa}$ ); 5) $\left.\mathrm{KNO}_{3}(-0,5 \mathrm{MPa}) ; 6\right) \mathrm{KNO}_{3}(-1,0 \mathrm{MPa})$; e 7) Testemunha (pré embebição apenas em água).

Rev. Bras. Pl. Med., Campinas, v.15, n.4, supl.I, p.655-663, 2013. 
As caixas gerbox foram cobertas com filme plástico para evitar a evaporação e as sementes incubadas em câmaras de germinação (Demanda Bioquímica de Oxigênio BOD) de $10^{\circ} \mathrm{C}$ e $20^{\circ} \mathrm{C}$ durante $12 \mathrm{~h}$ e $24 \mathrm{~h}$ ambos com luz direta. Após completar os tempos de embebição, as sementes foram retiradas da BOD e permaneceram em condição ambiente até atingirem o peso inicial apresentado antes do condicionamento. Em seguida, foram colocadas em caixas gerbox sobre duas folhas de papel filtro e mantidas em BOD em temperatura $20-30^{\circ} \mathrm{C}$ em regime fotoperiódico de $16 \mathrm{~h}$ de luz e $8 \mathrm{~h}$ no escuro .

Avaliou-se a porcentagem de germinação, 0 índice de velocidade de germinação, o comprimento da parte aérea, a relação raiz/parte aérea, o comprimento de raiz, e a massa seca das plântulas.

$O$ delineamento estatístico foi inteiramente casualizado em esquema fatorial de 7 tratamentos de pré-condicionamento, 2 temperaturas, e 2 tempos de pré-embebição. $\mathrm{O}$ ensaio foi conduzido com 4 repetições de 25 sementes. Todos os resultados foram submetidos à análise de variância e as médias comparadas pelo teste de Tukey a $5 \%$ de probabilidade.

Experimento 2: Efeito do sombreamento e do condicionamento osmótico sobre a emergência das sementes e crescimento inicial das mudas

O tratamento testemunha e os précondicionamentos que apresentaram os melhores resultados de germinação e vigor no laboratório em BOD sob alternância de temperatura e luz, foram semeados em bandejas de células contendo o substrato Plantmax ${ }^{\circledR}$ + terra + areia + cama de frango semi decomposta, nas proporções de 1:1:1:0,5 (v:v). Os tratamentos selecionados foram: $\mathrm{KNO}_{3}(-1,0 \mathrm{MPa})$ e PEG (-1,0 MPa). Após a semeadura, as bandejas permaneceram sob três condições: telado sombrite de $50 \%$, telado sombrite de $70 \%$ de sombreamento, e a pleno sol. Os níveis de sombreamento de 50 e de $70 \%$ foram obtidos com auxílio de telas pretas de nylon (sombrite). Todos os tratamentos receberam regas diárias por aspersão até atingir $70 \%$ da capacidade de campo. Após a emergência das plântulas foi avaliado a porcentagem de emergência $(E)$ e $o$ índice de velocidade de emergência [IVE $=\Sigma$ (ni/ ti)] segundo Popinigis (1985). O experimento foi realizado em delineamento inteiramente casualizado com 3 níveis de sombreamento, e 3 níveis de pré-condicionamento osmótico, contendo quatro repetições de 25 sementes.

Aos 20 dias após a emergência as plântulas foram transplantadas para sacos de polietileno de $20 \times 12 \mathrm{~cm}$ contendo como substrato terra + areia + cama de aviário, nas proporções em volume de
1:1:1 (v:v) e mantidas em seus respectivos locais de sombreamento.

As avaliações do crescimento e da qualidade das mudas foram determinadas aos 45, 70, 95, 120 e 145 dias de idade da muda nas seguintes características: a) altura da muda expressa em $\mathrm{cm}$ medida a partir do coleto até a gema apical; b) comprimento da raiz expressa em $\mathrm{cm}$ a partir da extremidade da raiz primária até o coleto, ambos medidos com régua milimetrada, c) diâmetro do coleto expresso em $\mathrm{mm}$ medido com paquímetro digital com precisão de $0,01 \mathrm{~mm}$; d) massa seca da parte aérea, e massa seca das raízes, expressa em gramas, determinadas em estufa de circulação forçada a $60^{\circ} \pm 5^{\circ} \mathrm{C}$, até a massa constante; e) RAD: relação da altura da parte aérea com o diâmetro do coleto; f) RPAR= relação massa seca da parte aérea com a massa seca das raízes; e g) IQD= índice de qualidade de Dickson obtido pela fórmula: IQD= [massa seca total/(RAD + RPAR)] (Dickson et al., 1960).

Determinou-se também o índice de clorofila, a transpiração, a condutância estomática, e a fotossíntese. As avaliações de transpiração, condutância estomática, e fotossíntese foram realizadas entre as 9:00 e 10:00 horas da manhã em folhas totalmente expandidas com auxílio do medidor portátil de fotossíntese $\mathrm{LCi}$, e a clorofila com SPAD 502.

Para cada espécie vegetal, o experimento foi realizado em delineamento inteiramente casualizado com quatro repetições de 15 mudas. Os resultados obtidos foram submetidos à análise de variância, e havendo significância, as médias de porcentagem de emergência, índice de velocidade de emergência, foram comparadas pelo teste de Tukey a $5 \%$ de probabilidade. Para as demais características, empregou-se análise de regressão.

\section{RESULTADO E DISCUSSÃO}

Não foi observada interação significativa entre os tratamentos para a porcentagem de germinação, relação raiz/parte aérea, e massa seca de plântula; entretanto, houve interação entre os fatores; tempo de pré-embebição e tratamentos pré-germinativos para o IVG, e entre temperaturas de incubação e tempos de pré-embebição para o comprimento da parte aérea e da raiz.

A porcentagem de germinação das sementes de angico não variou em relação à temperatura e o tempo de pré-embebição (Tabela 1). O osmocondicionamento não proporcionou aumento na germinação, pelo contrário, foi observada redução principalmente quando realizada com PEG isoladamente. Em relação à razão R/PA e massa seca, não houve diferença significativa para os

Rev. Bras. PI. Med., Campinas, v.15, n.4, supl.I, p.655-663, 2013. 
tratamentos de osmocondicionamento, embora a R/PA tenha sido maior quando a pré-embebição ocorreu a $20^{\circ} \mathrm{C}$.

O PEG isoladamente pode causar redução da viabilidade e vigor das sementes dependendo da concentração, conforme foi observado para outras espécies. Assim, para o angico branco (Anadenanthera colubrina (Vell.) Brenan), Rego et al. (2007), avaliando potenciais de 0 a $-1,4 \mathrm{MPa}$, verificaram que concentrações de PEG 6000 a partir de -0,8 MPa impediram a absorção de água, prejudicando a germinação que reduziu de 75,33 (testemunha) para $31,33(-0,8 \mathrm{MPa})$, enquanto que a velocidade de germinação de 15,34 (testemunha) reduziu para 4,42 (a partir do potencial -0,6 MPa). Entretanto, Perez et al. (2001) observaram limites maiores de tolerância ao estresse hídrico ao testar potenciais de 0 a -2,0 MPa em sementes de canafístula (Peltophorum dubium L.), e verificaram que os limites de tolerância para a germinação situaram-se entre $-1,4$ e -1,6 MPa.

De maneira semelhante, Jeller \& Perez (2001), avaliando os efeitos do estresse hídrico e salino no processo germinativo das sementes de canafístula (Senna spectabilis (DC.) H.S. Irwin \& Barneby) também observaram redução da germinação embora a relação R/PA e massa seca de plântulas não tenham sido influenciadas pelos tratamentos.

O IVG também reduziu com o osmocondicionamento em PEG observando maior velocidade de germinação em sementes tratadas com $\mathrm{KNO}_{3}$ (Tabela 2). As sementes de angico comportaram-se de maneira indiferente quanto às temperaturas de pré-embebição e quanto ao tempo. Somente as sementes sem pré-condicionamento apresentaram maior IVG com a pré-embebição por 12 horas. Os tratamentos de osmo-condicionamento dentre as condições e concentrações testadas, reduziram a velocidade de germinação e apresentaram resultados insatisfatórios.

Observando a Tabela 3 , verifica-se que o CPA das plântulas não variou quanto às temperaturas e que a $20^{\circ} \mathrm{C}$ sementes embebidas por 12 horas apresentaram maiores tamanhos. $\mathrm{O} C R$ das plântulas provenientes de sementes embebidas a $10^{\circ} \mathrm{C}$ foi menor, entretanto a $20^{\circ} \mathrm{C}$ não houve variação.

No segundo experimento, não foi observada interação significativa entre os tratamentos de sombreamento com os pré-condicionamentos osmóticos para as características porcentagem de emergência e índice de velocidade de emergência, as quais não diferiram sob as três condições de luminosidade.

Esses resultados podem ser atribuídos à plasticidade fenotípica dessas espécies, a qual é de grande importância ecológica, pois as sementes podem germinar em qualquer situação de luz em que se encontram. Sementes de angico submetidas ao condicionamento osmótico com $\mathrm{KNO}_{3}(-1,0 \mathrm{MPa})$ apresentaram maior índice de velocidade de emergência embora não tenha sido observada variação significativa na porcentagem de emergência (Tabela 4). Nesse experimento, mais uma vez se observa o efeito negativo do PEG para as sementes de angico preto.

Os tratamentos de condicionamento

TABELA 1. Porcentagem de germinação (\% G), relação raiz/parte aérea (R/PA) e massa seca (MS) das plântulas de angico preto (Anadenanthera falcata Benth. Speg.) em função de diferentes tratamentos de précondicionamento osmótico. UFGD, Dourados-MS, 2009.

\begin{tabular}{l|c|c|c}
\hline Tratamentos & \% G & R/PA & MS (g) \\
\hline $10^{\circ} \mathrm{C}$ & $89,59 \mathrm{a}$ & $0,77 \mathrm{~b}$ & $0,11 \mathrm{a}$ \\
$20^{\circ} \mathrm{C}$ & $88,32 \mathrm{a}$ & $0,85 \mathrm{a}$ & $0,11 \mathrm{a}$ \\
& & & \\
Pré-embebição 12h & $90,76 \mathrm{a}$ & $0,76 \mathrm{a}$ & $0,11 \mathrm{a}$ \\
Pré-embebição 24h & $89,43 \mathrm{a}$ & $0,77 \mathrm{a}$ & $0,11 \mathrm{a}$ \\
& & & \\
Testemunha & $92,22 \mathrm{a}$ & $0,82 \mathrm{a}$ & $0,11 \mathrm{a}$ \\
$\mathrm{KNO}_{3}(-1,0 \mathrm{MPa})$ & $91,33 \mathrm{a}$ & $0,87 \mathrm{a}$ & $0,11 \mathrm{a}$ \\
$\mathrm{KNO}(-0,5 \mathrm{MPa})$ & $90,00 \mathrm{ab}$ & $0,87 \mathrm{a}$ & $0,11 \mathrm{a}$ \\
$\mathrm{PEG}(-1,0 \mathrm{MPa})+\mathrm{KNO}_{3}(-1,0 \mathrm{MPa})$ & $88,00 \mathrm{ab}$ & $0,80 \mathrm{a}$ & $0,11 \mathrm{a}$ \\
$\mathrm{PEG}(-0,5 \mathrm{MPa})+\mathrm{KNO}_{3}(-0,5 \mathrm{MPa})$ & $87,78 \mathrm{ab}$ & $0,78 \mathrm{a}$ & $0,11 \mathrm{a}$ \\
$\mathrm{PEG}(-1,0 \mathrm{MPa})$ & $87,33 \mathrm{ab}$ & $0,72 \mathrm{a}$ & $0,11 \mathrm{a}$ \\
$\mathrm{PEG}(-0,5 \mathrm{MPa})$ & $86,00 \mathrm{~b}$ & $0,81 \mathrm{a}$ & $0,11 \mathrm{a}$ \\
\hline $\mathrm{CV}(\%)$ & 5,83 & 21,27 & 12,19 \\
\hline
\end{tabular}

Médias seguidas pelas mesmas letras minúsculas, na linha, e maiúsculas, na coluna, não diferem entre si pelo teste de Tukey a $5 \%$ de probabilidade.

Rev. Bras. PI. Med., Campinas, v.15, n.4, supl.I, p.655-663, 2013. 
TABELA 2. Índice de velocidade de germinação (IVG) das sementes de angico preto (Anadenanthera falcata Benth. Speg.) em função de diferentes tempos e tratamentos de pré-condicionamento osmótico. UFGD, Dourados-MS, 2009.

\begin{tabular}{lcc}
\hline Tratamentos & Pré-embebição por 12h & Pré-embebição por 24h \\
\hline Testemunha & 6,34 a B & $5,59 \mathrm{~b} \mathrm{~B}$ \\
$\mathrm{KNO}_{3}(-1,0 \mathrm{MPa})$ & $7,24 \mathrm{a} \mathrm{A}$ & $7,13 \mathrm{a} \mathrm{A}$ \\
$\mathrm{KNO}_{3}(-0,5 \mathrm{MPa})$ & $6,73 \mathrm{a} \mathrm{AB}$ & $6,66 \mathrm{a} \mathrm{A}$ \\
$\mathrm{PEG}(-1,0 \mathrm{MPa})+\mathrm{KNO}_{3}(-1,0 \mathrm{MPa})$ & $3,83 \mathrm{a} \mathrm{C}$ & $3,61 \mathrm{a} \mathrm{C}$ \\
$\mathrm{PEG}(-0,5 \mathrm{MPa})+\mathrm{KNO}_{3}(-0,5 \mathrm{MPa})$ & $3,72 \mathrm{a} \mathrm{C}$ & 3,81 a C \\
PEG $(-1,0 \mathrm{MPa})$ & 3,74 a C & 3,61 a C \\
PEG $(-0,5 \mathrm{MPa})$ & 3,40 a C & 3,44 a C \\
\hline CV\% & &
\end{tabular}

Médias seguidas pelas mesmas letras minúsculas, na linha, e maiúsculas, na coluna, não diferem entre si pelos testes $\mathrm{F}$ e de Tukey a $5 \%$ de probabilidade

TABELA 3. Comprimento da parte aérea (CPA) e comprimento da raiz (CR) das plântulas de angico preto (Anadenanthera falcata Benth. Speg.) em função de diferentes tempos e temperaturas de pré-condicionamento osmótico. UFGD, Dourados-MS, 2009

\begin{tabular}{|c|c|c|c|c|}
\hline \multirow{3}{*}{ Tratamentos } & \multicolumn{2}{|c|}{$\mathrm{CPA}(\mathrm{cm})$} & \multicolumn{2}{|r|}{$\mathrm{CR}(\mathrm{cm})$} \\
\hline & & & & \\
\hline & $10^{\circ} \mathrm{C}$ & $20^{\circ} \mathrm{C}$ & $10^{\circ} \mathrm{C}$ & $20^{\circ} \mathrm{C}$ \\
\hline Pré-embebição 12h & 7,24 a $A$ & 7,81 a $A$ & $4,91 \mathrm{~b} \mathrm{~A}$ & 6,43 a $A$ \\
\hline Pré-embebição 24h & 7,38 a $A$ & 7,30 a $B$ & 5,16 a $A$ & 5,94 a $A$ \\
\hline CV \% & \multicolumn{2}{|c|}{13,46} & \multicolumn{2}{|c|}{21,60} \\
\hline
\end{tabular}

Médias seguidas pelas mesmas letras minúsculas, na linha, e maiúsculas, na coluna, não diferem entre si pelo teste $\mathrm{F}$ a $5 \%$ de probabilidade.

osmótico também não influenciaram a altura, o comprimento da raiz, o diâmetro do coleto, a massa seca da parte aérea, e a massa seca da raiz das mudas. A altura foi maior aos 145 dias

TABELA 4. Porcentagem de emergência (E) e índice de velocidade de emergência (IVE) das sementes de angico preto (Anadenanthera falcata Benth. Speg.) em função de diferentes níveis de sombreamento e diferentes tratamentos de pré-condicionamento osmótico. UFGD, Dourados-MS, 2009.

\begin{tabular}{lcc}
\hline Tratamentos & $\mathrm{E}(\%)$ & IVE \\
\hline 70\% sombreamento & $86,22 \mathrm{a}$ & $3,10 \mathrm{a}$ \\
$50 \%$ sombreamento & $83,55 \mathrm{a}$ & $3,11 \mathrm{a}$ \\
Pleno Sol & $83,44 \mathrm{a}$ & $3,10 \mathrm{a}$ \\
& & \\
$\mathrm{KNO}_{3}(-1,0 \mathrm{MPa})$ & $84,33 \mathrm{a}$ & $3,87 \mathrm{a}$ \\
$\mathrm{PEG}_{(-1,0 \mathrm{MPa})}$ & $84,88 \mathrm{a}$ & $2,62 \mathrm{~b}$ \\
Testemunha & $84,00 \mathrm{a}$ & $2,82 \mathrm{~b}$ \\
\hline CV \% & 8,22 & 15,16 \\
\hline
\end{tabular}

Médias seguidas pela mesma letra nas colunas não diferem entre si pelo teste de Tukey a $5 \%$ de probabilidade de idade quando as mudas foram submetidas aos sombreamentos de 50 e $70 \%$ (Figura 1a). O sombreamento também induziu maior crescimento em altura de outras espécies como foi observado por Scalon et al. (2008) em croton (Croton urucurana Baill) a $50 \%$ de sombreamento, por Rego \& Possamai (2006) em jequitibá rosa (Cariniana legalis Martius) mantidas a $36 \%$ de sombreamento e por Carvalho et al. (2006) com plantas de licuri (Syagrus coronata (Mart.) Becc.) submetidas a 70\% de sombreamento.

A capacidade de rápido crescimento em ambiente sombreado é um mecanismo importante de adaptação da espécie que constitui uma valiosa estratégia para escapar às condições de baixa disponibilidade de luz (Moraes Neto et al., 2000). Ao longo das avaliações, o maior comprimento de raiz foi observado a pleno sol, entretanto, ao final, foi maior nas mudas a $70 \%$ de sombreamento (Figura 1b).

As mudas de angico apresentaram crescimento linear do diâmetro, sendo observado a partir dos 120 dias de idade aumento no diâmetro quando submetidas a maiores níveis de luz (Figura 1c).

Rev. Bras. PI. Med., Campinas, v.15, n.4, supl.I, p.655-663, 2013. 
a)

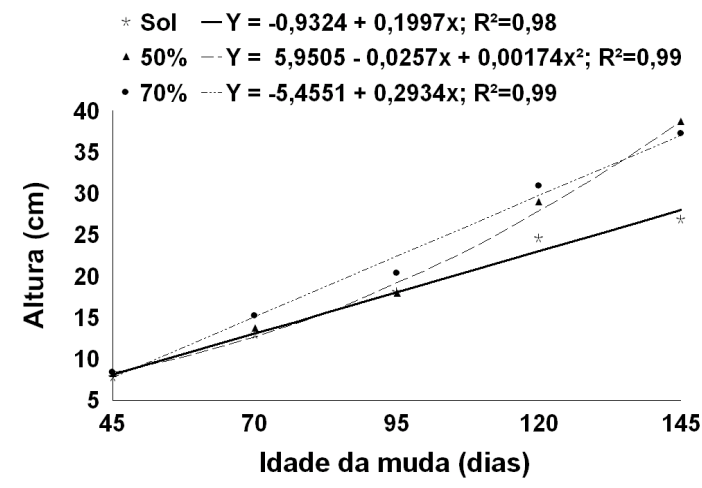

c)

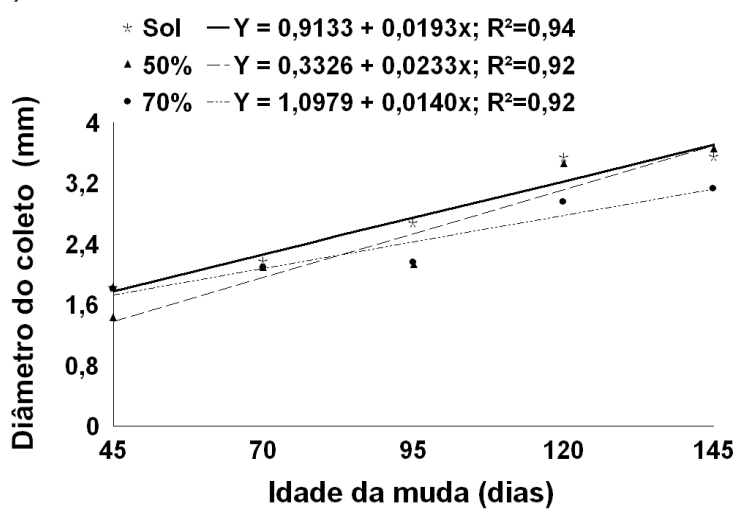

Os dados observados confirmam os encontrados na literatura, que em níveis de maior luminosidade, há maior produção dos fotoassimilados e de reguladores de crescimento, em razão de maior fotossíntese, o que reflete no maior desenvolvimento em espessura do caule. Rego \& Possamai (2006), analisando o efeito do sombreamento sobre o teor de clorofila e crescimento inicial de mudas de jequitibá-rosa, também observaram maior diâmetro do coleto em plantas submetidas a maiores níveis de luz. A maior massa seca da parte aérea foi observada em mudas

a)

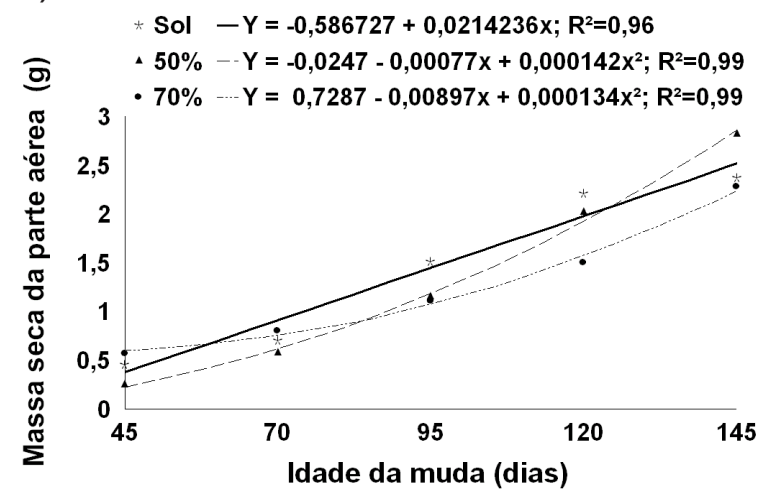

b)

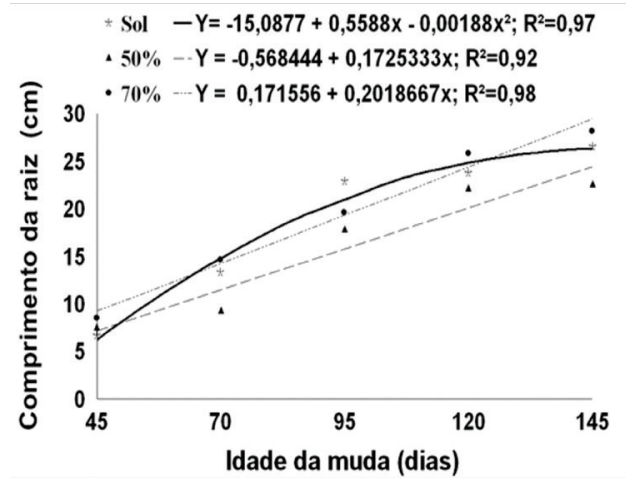

FIGURA 1. Altura (a), comprimento da raiz (b) e diâmetro do coleto (c) de mudas de Anadenanthera falcata Benth. Speg. em função da idade das mudas. a $50 \%$ de sombreamento aos 145 dias de idade (Figuras 2a).

Embora não tenha sido observado diferenças no comprimento da raiz dentre os três níveis de sombreamento, as mudas a pleno sol apresentaram massa seca de raiz muito superior à das mudas sombreadas (Figuras $2 b$ ). Esses dados podem ser explicados baseados no fato de que, a pleno sol, o solo tende a perder mais água por evaporação, o que reduz a disponibilidade hídrica para as raízes e, nessa situação, ocorre redução do crescimento da parte aérea e maior translocação

b)

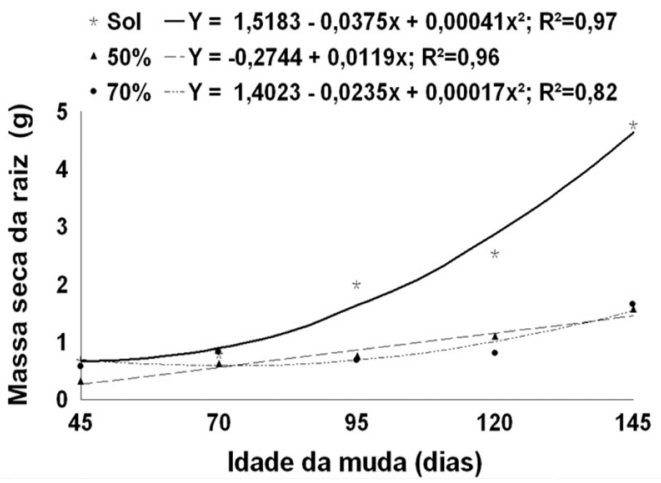

FIGURA 2. Massa seca da parte aérea (a) e massa seca da raiz (b) de mudas de Anadenanthera falcata Benth. Speg. em função da idade das mudas. 
de assimilados para o sistema radicular resultando no maior crescimento das raízes facilitando a absorção de água nas camadas mais profundas do solo. Assim, mudas com maior biomassa de raiz provavelmente têm maior chance de sobreviver ao estresse hídrico da estação de seca quando em ambiente natural, e essa característica, portanto, é extremamente importante para o sucesso de atividades de plantio de mudas (Longman, 2003; Figueroa et al., 2004; Taiz \& Zeiger, 2004)

Assim, observa-se tendência de maior direcionamento da massa seca para a parte aérea em plantas sombreadas, e de maior massa seca de raízes em plantas crescidas sob maior nível de luz, como foi verificado em S. coronata (Mart.) Becc. (Carvalho et al., 2006), C. legalis Martius (Rego \& Possamai, 2006). Scalon et al. (2006) observaram para mudas de aroeira do sertão (Schinus terebinthifolius Raddi) que, embora a altura seja maior sob sombreamento de $50 \%$, o diâmetro variou, e o peso seco total e a área foliar foram maiores a pleno sol concluíndo que essa condição é a mais indicada para a produção daquelas mudas.

No presente trabalho, o fato da menor massa seca da parte aérea de mudas a $70 \%$ de sombreamento ser comparável aos valores encontrados a pleno sol, talvez se deva ao fato de que o nível de sombreamento possa ter sido muito elevado, refletindo em menor produção de fotoassimilados e, consequentemente, menor incremento da massa seca da parte aérea.

Observando a Tabela 5 verifica-se que quanto maior foi o grau de luminosidade, maior foi a transpiração, a condutância estomática, e a fotossíntese das mudas de angico. Resultados semelhantes foram observados por Lima Junior et al. (2006), que estudando os aspectos fisioanatômicos de plantas jovens de camboatã (Cupania vernalis Camb.) submetidas a diferentes níveis de sombreamento de $0,30,50$ e $70 \%$ só não observaram diferença significativa para a transpiração. Já os tratamentos de condicionamento osmótico não influenciaram a transpiração, a condutância estomática, e a fotossíntese das mudas de angico.

Resultados semelhantes foram observados por Welander \& Otosson (2000), avaliando o crescimento de mudas de carvalho (Quercus robur L.), quando observaram maiores taxas de transpiração com o aumento da irradiância, e por Alvarenga et al. (2003) avaliando o efeito de diferentes níveis de luz no crescimento inicial de plantas de Croton urucurana Baill., que verificaram maiores taxas fotossintéticas em plantas cultivadas em níveis mais elevados de irradiância. Em relação à condutância estomática, também foi observada maiores valores para as mudas de andiroba (Carapa guianensis Aubl.) (Costa \& Marrenco, 2007) quando a radiação solar é máxima e o potencial hídrico da folha ainda não atingiu os valores mínimos passíveis de induzir o fechamento estomático.

Os tratamentos de condicionamento osmótico não influenciaram os parâmetros de qualidade das mudas de angico. A relação altura/ diâmetro teve um crescimento linear, apresentando maiores valores aos 145 dias de idade da muda, sob $70 \%$ de sombreamento. Maiores valores de RAD indicam estiolamento das plantas, aspecto que foi observado nas mudas sombreadas (Figura 3a).

A razão altura/diâmetro do coleto é um parâmetro que indica qualidade das mudas a serem levadas ao campo, uma vez que se espera o equilíbrio no desenvolvimento, pois plântulas estioladas têm maior probabilidade de tombar, o que pode resultar em alteração do padrão de qualidade da planta adulta. A característica de estiolamento em ambientes sombreados é uma resposta bastante comum, podendo ser atribuída ao maior investimento no alongamento celular. Esse comportamento é um mecanismo importante de adaptação dessas

TABELA 5. Transpiração (E), condutância estomática (Gs) e fotossíntese (F) de mudas de Anadenanthera falcata Benth. Speg. aos 145 dias após a emergência. Dourados-MS, 2009.

\begin{tabular}{|c|c|c|c|}
\hline \multirow{2}{*}{ Tratamentos } & $E$ & Gs & $\mathbf{F}$ \\
\hline & Mmol $m^{-2} \mathbf{s}^{1}$ & Mol $m^{-2} s^{1}$ & $\mu \mathrm{mol} \mathrm{m} \mathrm{m}^{-2} \mathrm{~s}^{1}$ \\
\hline Pleno Sol & $1,31 \mathrm{a}$ & $0,23 a$ & $7,10 \mathrm{a}$ \\
\hline $50 \%$ sombreamento & $0,87 \mathrm{~b}$ & $0,16 \mathrm{~b}$ & $5,90 \mathrm{~b}$ \\
\hline $70 \%$ sombreamento & $0,86 \mathrm{~b}$ & $0,15 b$ & $5,72 b$ \\
\hline $\mathrm{KNO}_{3}(-1,0 \mathrm{MPa})$ & $1,06 a$ & $0,17 \mathrm{a}$ & $6,21 \mathrm{a}$ \\
\hline PEG $(-1,0 \mathrm{MPa})$ & $0,98 a$ & $0,18 a$ & $6,26 a$ \\
\hline Testemunha & $1,01 \mathrm{a}$ & $0,19 a$ & $6,26 \mathrm{a}$ \\
\hline $\mathrm{CV} \%$ & 10,02 & 16,94 & 6,85 \\
\hline
\end{tabular}

Médias seguidas pela mesma letra nas colunas não diferem entre si pelo teste de Tukey a $5 \%$ de probabilidade

Rev. Bras. PI. Med., Campinas, v.15, n.4, supl.I, p.655-663, 2013. 
a)

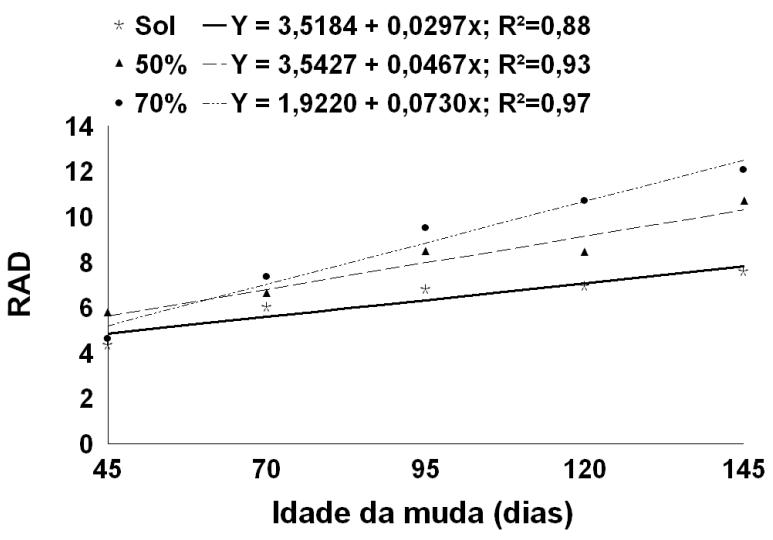

b)

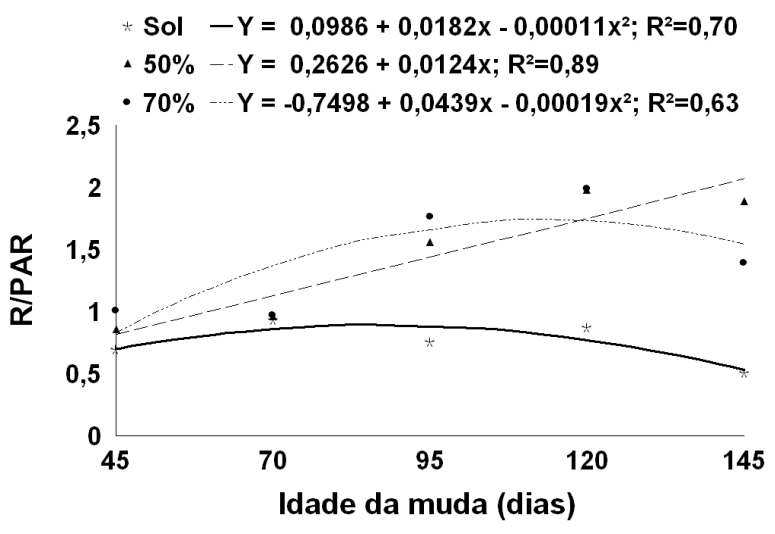

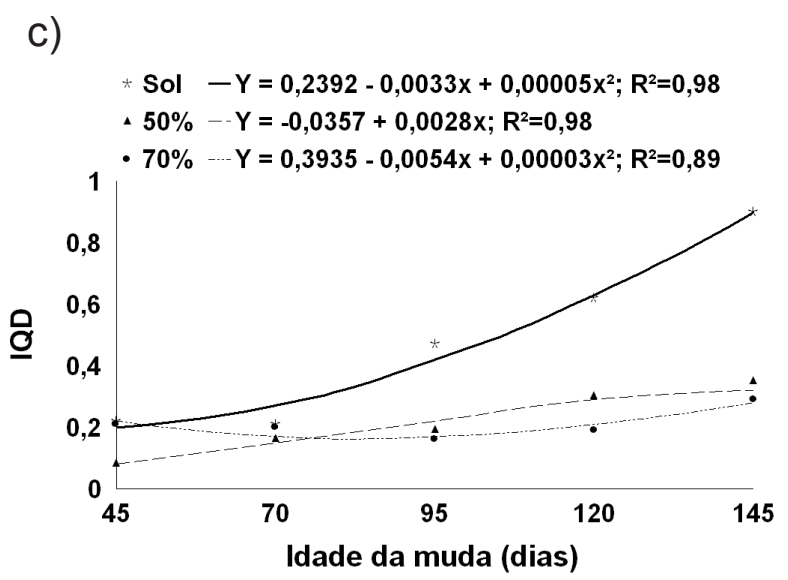

FIGURA 3. RAD (a), RPAR (b) e IQD (c) de mudas Anadenanthera falcata Benth. Speg. em função da idade das mudas. $R A D=$ relação altura/diâmetro do coleto, $R P A R=$ relação matéria seca da parte aérea / matéria seca das raízes, e $I Q D=$ índice de qualidade de Dickson.

espécies, as quais, provavelmente, mantêm maior quantidade de fotoassimilados para a parte aérea, proporcionando maior alongamento celular (Moraes Neto et al., 2000). Esse maior crescimento sob sombreamento pode também ser atribuído às temperaturas mais amenas nas folhas, levando à abertura dos estômatos e a fixação de carbono pelas plantas (Taiz \& Zeiger, 2004).

Os maiores valores de RPAR aos 120 dias de idade das mudas foram observados sob $50 \%$ e $70 \%$ de sombreamento (Figura $3 b$ ), já que nessa situação as raízes apresentavam menor comprimento de raiz. Resultados semelhantes também foram observadas para mudas de sabiá (Mimosa caesalpiniifolia Benth.) e chichá (Sterculia foetida L) por Câmara \& Endres (2008) quando sob aumento da exposição à radiação fotossintetizante apresentaram aumento na partição de assimilados para o sistema radicular. O mesmo ocorreu para mudas de $S$. coronata (Mart.) Becc., nas quais houve tendência de redução na razão de massa raiz/parte aérea no tratamento que recebeu menor nível de luz (Carvalho et al., 2006). Fonseca et al.
(2002) observaram que a causa da diminuição da massa radicular sob sombreamento deve-se ao fato de que as mudas produzidas a pleno sol, por estarem sujeitas à restrição hídrica, acumulam massa seca no sistema radicular, em detrimento do acúmulo de assimilados na parte aérea. Câmara \& Endres (2008) sugerem que talvez a planta esteja preparando-se para condições com maior demanda transpiratória ou condições oligotróficas, nas quais a presença de luminosidade intensa sugere um ambiente com menos nutrientes e água.

Os maiores valores de IQD foram obtidos em mudas mantidas a pleno sol aos 145 dias de idade das mudas (Figura 3c), sendo o IQD um bom indicador de qualidade de mudas, pois é considerado indicativo de robustez e equilíbrio da distribuição da biomassa, sendo importante parâmetro a ser empregado na avaliação da qualidade (Fonseca et al., 2002).

As sementes de angico não apresentaram aumento na germinação quando pré-embebidas embora tenha ocorrido redução no IVG. Os tratamentos de osmo-condicionamento reduziram a 
germinação e apresentaram resultados insatisfatórios quando se compara à testemunha.

Os níveis de sombreamento avaliados não influenciaram na emergência do angico, entretanto, sementes tratadas com $\mathrm{KNO}_{3}(-1,0 \mathrm{MPa})$ tiveram maior IVE.

Mudas a pleno sol apresentaram melhor desenvolvimento e qualidade até os 145 dias de idade.

\section{AGRADECIMENTO}

Ao Conselho Nacional de Desenvolvimento Científico e Tecnológico (CNPq) e a Fundação de Apoio ao Desenvolvimento do Ensino, Ciência e Tecnologia do Estado de Mato Grosso do Sul (FUNDECT), pelo auxílio financeiro e bolsas concedidas.

\section{REFERÊNCIA}

ALVARENGA, A.A. et al. Effects of different light leveld on the initial growth and phothosynthesis of Croton urucurana Baill. In. southeastern Brazil. Revista Árvore, v.27, n.1, p.53-7, 2003.

CÂMARA, C.A.; ENDRES, L. Desenvolvimento de mudas de duas espécies arbóreas: Mimosa caesalpiniifolia Benth. e Sterculia foetida L. sob diferentes níveis de sombreamento em viveiro. Floresta, v.38, n.1, p.11-7, 2008.

CARVALHO, P.E.R. Espécies arbóreas brasileiras. Brasília:Embrapa Informação Tecnológica; Colombo, PR: Embrapa Florestas, 2003. 1039p.

CARVALHO, N.O.S. et al. Crescimento inicial de plantas de licuri (Syagrus coronata (Mart.) Becc.) em diferentes níveis de luminosidade. Revista Árvore, v.30, n.3, p.351-7, 2006.

COSTA G.F.; MARENCO R.A. Fotossíntese, condutância estomática e potencial hídrico foliar em árvores jovens de andiroba (Carapa guianensis). Acta Amazonica, v.37, n.2, p.229 -34, 2007.

DICKSON, A.; LEAF, A.L.; HOSNER, J.F. Quality apprasial of withe spruce and White pine seedling stock in nurseries. Forest Chronicle, v.36, p.10-13, 1960.

FIGUEIRÔA, M.F.; BARBOSA, D.C.A.; SIMABUKURO, E.A. Crescimento de plantas jovens de Myracrodruon urundeuva Allemão (Anacardiaceae) sob diferentes regimes hídricos. Acta Botânica Brasílica, v.18, n.3, p.1-14, 2004.

FONSECA, E.P. et al. Padrão de qualidade de mudas de Trema micrantha (L.) Blume, produzidas sob diferentes períodos de sombreamento. Revista Árvore, v.26, n.4, p.515-23, 2002.

GONÇALVES, F.G.; GOMES, S.S.; GUILHERME, A.L. Efeito da luz na germinação de sementes de Guatteria gomeziana (Unonopsis lindmanii R. E. FR.). Revista Científica Eletrônica de Engenharia Florestal, v.8, p.11-7, 2006.

JELLER, H.; PEREZ, S.J.G.A. Efeitos dos estresses hídrico e salino e da ação de giberelina em sementes de Senna spectabilis. Ciência Florestal, v.11, n.2, p.93-104, 2001.

LARCHER, W. Ecofisiologia vegetal. São Carlos: Rima Artes e Textos, 2000. 531p.

LIMA JÚNIOR, E.C. et al. Aspectos fisioanatômicos de plantas jovens de Cupania vernalis Camb. submetidas a diferentes níveis de sombreamento. Revista Árvore, v.30, n.1, p.33-41, 2006.

LONGMAN, K.A. Raising seedlings of tropical trees. Londres: CommonwealthScience Council, 2003. 156p.

MARTINS, S.V.; SILVA, N.R.S. Considerações sobre conservação e restauração de fragmentos florestais. Folha Florestal - Departamento de Engenharia Florestal da UFV, Viçosa: n. 99, p. 7- 8, 2001.

MORAES NETO, S.P. et al. Crescimento de mudas de algumas espécies arbóreas que ocorrem na mata atlântica em função do nível de luminosidade. Revista Árvore, v.24, n.1, p.35-45, 2000.

MARCOS FILHO, J. Fisiologia de sementes de plantas cultivadas. Piracicaba: Fealq, 2005. 495p.

MATO GROSSO DO SUL. Atlas Multireferencial. Campo Grande: Secretaria de Planejamento e Coordenação Geral, 1990.

NIETSCHE, S. et al. Tamanho da semente e substratos na germinação e crescimento inicial de mudas de cagaiteira. Ciência e Agrotecnologia, v.28, n.6, p.1321-5, 2004.

PEREZ, S.C.J.G.A.; FANTI, S.C.; CASALI, C.A. Influência da luz na germinação de sementes de canafístula submetidas ao estresse hídrico. Bragantia, v.60, n.3, p.155-6, 2001.

POPINIGIS, F. Fisiologia da semente. Brasília: Agiplan, 1985. p.289.

REGO, G.M.; POSSAMAI, E. Efeito do sombreamento sobre o teor de clorofila e crescimento inicial do jequitibá-rosa. Boletim de Pesquisa Florestal. Embrapa Floresta, Colombo, v. 53, p. 179-94, 2006.

REGO, S.S. et al. Influência de potenciais osmóticos na germinação de sementes de Anadenanthera colubrina (Veloso) Brenan (Angico-branco) - Mimosaceae. Revista Brasileira de Biociências, v.5, p.549-51, 2007.

SANTOS, L.F. Levantamento de Plantas medicinais nas fazendas Santa Madalena e Lagoa Azul em Dourados, MS. Monografia de final de Curso. Universidade Federal de Mato Grosso do Sul. 2002.67p.

SCALON, S.P.Q. et al. Desenvolvimento de mudas de Aroeira (Schinus terebinthifolius) e sombreiro (Clitoria fairchildiana) sob condições de sombreamento. Ciência e Agrotecnologia, v.30, n.1, p.166-9, 2006.

SCALON, S.P.Q. et al. Crescimento inicial de mudas de sangra-d'água (Croton urucurana Baill.) sob sombreamento e aplicação de giberelina. Revista Brasileira de Plantas Medicinais, v.10, n.3, p.61-6, 2008 SCALON FILHO, H.; SCALON, S. P. Q.; MUSSURY, R. M. Armazenamento e germinação de sementes de angico preto . In:CONGRESSO BRASILEIRO DE OLERICULTURA, 46, 2006, Goiânia, Resumos... Brasília, SOB, 2006, CDROM.

TAIZ, L.; ZEIGER, F. Fisiologia Vegetal. Porto Alegre:Artmed, 3. ed, 2004. p.719.

WELANDER, N.T.; OTOSSON, B. The influence of low light, droughtand fertilization on transpiration and growt in young seedllings of Quercus robur. Forest ecology and Management, v.127, n1/3, p. 139-51, 2000. 